\title{
Evaluation of Dominant Microbial Air Pollutants in Hospital Environments and Nearby Areas in Albania
}

\author{
Erjon Troja ${ }^{1 *}$, Ranela Ceci ${ }^{2}$, Albana Markaj ${ }^{3}$, Eltion Dhamo ${ }^{3}$, Rozana Troja ${ }^{3}$ \\ 1 University of Medicine, Faculty of Medicine, Department of Pharmacy, Tirana, Albania \\ 2 National Agency of Drugs and Medical Devices, Tirana, Albania \\ 3 University of Tirana, Faculty of Natural Sciences, Department of Industrial Chemistry, Tirana, Albania \\ Corresponding author's e-mail: erjon.troja@umed.edu.al
}

\begin{abstract}
Nowadays, one of the most important and essential aspects of having a healthy and safe life is the air safety and its quality in indoor and outdoor environments. In the air, there are not only chemical pollutants but also biological ones, with specific impacts. Hospital environments are among the most likely to be affected by the microbiological contamination of the air; therefore its quality is particularly important. Pathogenic microorganisms, which may be present in the air, can cause nosocomial infections in hospitalized patients, with compromised immune system or other medical conditions. This paper reflects the evaluation of microbiological air contamination, in different hospital environments and nearby areas, in the city of Tirana. The microbial air quality has been monitored during the period of 2009-2018, performing evaluations every three years, in the same area and the same time of the year. In order to build a database for understanding the impact of developmental changes on the air microbiological loads, results of similar studies conducted earlier, during 2007 and 2008 were also taken into consideration. The above-mentioned period was selected because of the changes in the infrastructure and indoor environments of the monitored area, where many patients have been treated for years. Changes have been made over the years to hospital structures and surroundings, including recreational facilities, clinical service units, as well as main and connecting roads, etc. The obtained results, which were compared over the years, provided a clear view of the changing microbiological air loads, influenced by the improvements of indoor and outdoor areas. The morphological studies of the observed, isolated, purified and identified microorganisms revealed the presence of specific mold loads, with the dominance of the species of Aspergillus genus and those of the group Fungi imperfecti. Over the years, a decrease in the total number was observed (from $10^{3}$ to $10^{1}$ ), together with a smaller number of bacteria $\left(10^{12}\right)$, in the monitored environments.
\end{abstract}

Keywords: microbial contamination, air quality, hospital environments, Tirana, Albania

\section{INTRODUCTION}

Microbiological contamination is part of general environmental pollution, having an active impact on the negative consequences that "contamination" causes in general to humans, water, vegetation, and other biological ecosystems. The contamination with microorganisms results from several factors, such as polluted air, waters contaminated with organic substances, industrial pollution, human activities, and does not exclude the increase of the presence of natural contaminants, carriers of pathogenic and saprophytic microbiological loads, etc. Together with urban development, change and modernization of classical building structures, as well as population growth due to the migration and immigration phenomena, researchers have focused their attention on different types of pollution such as acid rain, poisonous and/or potentially poisonous gas deposition, contaminants from medicines used in agriculture or industrial waste chemicals, etc. Later, important research studies were expanded with the coexistence of microbial contaminants with other forms of pollution. These types of pollutants, which belong to taxonomically well-studied 
microorganisms, are extending their pollutant character by being organized in the form of biofilms, well-organized multi-cell layers, much more active and stable species compared to the segregated cells. Thus, nowadays, their destruction requires a combination of classic methods with new techniques, such as the use of ultrasound or pulsed electric fields. The potential risk of contamination by clustered microorganisms has required the identification of environmental microbial contaminants and selection of those cases, where microorganisms are organized in the form of biofilms. Due to their high resistance to destruction, biofilms prevent the cleaning of the environment, where they are located.

Microbial contamination of the environment includes the air pollution caused by specific genera and species. From the air, they are dispersed to the water, surfaces, soils, human beings, etc. Various factors affect the microbiological air pollution, for example the transfer of microorganisms from one environment to another, climatic changes in the places under monitoring, etc [Bekkari et al. 2016, Ekhaise et al. 2012, Prifti et al. 2004].

Hospital environments are sources for the distribution of contaminating microorganisms, which are transferred to nearby areas or vice versa. The minor spread of infections within the areas where patients are undergoing therapy and rehabilitation procedures is also associated with the attempts to contain the infections from microorganisms, polluted environments, polluted air, visitors, or contaminated zones around health institutions.

The hospital-acquired infections, also called hospital-associated infections (nosocomial infections), are associated clinically (or not) with some microorganisms:

- in the patient upon admission to hospital as a result of the health care he has received

- as a result of a preliminary treatment outpatient,

- transmitted by hospital staff during the practice of the professional activity, etc. [Kika et al. 2014]

The airborne microorganisms can be transmitted through aerosols and can survive for a long time [Pallabi 2018], especially if they are capable of forming the adhesion phase, in the formation of biofilms.

In different countries, hospital infections are not in the same rate [Bekkari et al. 2016, Ducel et al 2012, Kika et al. 2014, Pallabi 2018,
Qudiesat et al. 2019, Troja 2014]. Overall development, application of modern medical techniques, population awareness for personal hygiene, and community cleanliness, are important factors that can reduce these infections and their damage. Currently, Albanian specialists in the medical field, including hygienists and microbiologists are working hard to control hospital infections (according to Protocol for the Control and Prevention of Hospital Infections-Albania 2012, air evaluation will be performed with sedimentation method-IMA plates Rodak with blood agar media and plates with SDA, total load $1 \times 10^{2}-5 \times 10^{2}$ microorganisms $/ \mathrm{m}^{3}$ air; ultraclean air $10 \mathrm{CFU} / \mathrm{m}^{3}$ )

We are conscious that there is still a lot to be done to determine the levels of microbiological pollution in the areas that can be monitored (IMA in surroundings and indoors) [Grisoli et al. 2019, Syed et al. 2016, Traistaru et al 2013].

\section{SAMPLING AND METHODS OF ANALYSIS}

The study protocol and methodology were focused on appropriate sampling and selection of the methods of microbiological analysis.

\section{Sampling}

The assessment of microbiological air pollution, as an integral part of its overall pollution, is an appropriate way to show the extent of the pollution and define the appropriate intervening time, to prevent and eliminate it. In this study, the air in some healthcare environments was analyzed in detail. Our objective was to provide an overview of the microbiological air pollution degree in such environments, where microbial content must be minimal, resulting in that the infections by airborne microorganisms could be considered impossible. The research also aimed to show the current situation regarding the air in general terms, and its possible consequences in healthcare units. In 2018, three encoded hospitals in University Hospital Center "Mother Teresa" and University Obstetric \& Gynecologic Hospital "Queen Geraldine", in Tirana, Albania, were selected for sampling:

- Hospital 1: garden-M001; reception hallM002; hospital ward-M003; reanimation-M004

- Hospital 2: hospital ward 1-M011; patient room 1-M012; 
- Hospital 3: hospital ward 1-M111; patient room 1-M112;

- Hospital 4: garden 1-M1; garden 2-M2; reception hall-M3; hospital ward-M4; patient room (at that moment full of people)-M5.

Over the years, comparative studies were performed by considering some similar environments (comparative studies for gardens, reception hall and hospital ward of Hospital 4 (renovated).

- Hospital 4: garden 1-M1-19; garden 2-M2-19; reception hall-M3-19; hospital ward-M4-19; patient room-M5 (year 2019).

- Hospital 4: garden 1-M1-10; garden 2-M2-10; reception hall-M3-10; hospital ward-M4-10; patient room M5 (year 2010).

The following samples were selected to detect pathogens:

- Hospital 4: garden 1-M1; garden 2-M2; reception hall -M3; hospital ward-M4 (year 2018 - incubation in $37^{\circ} \mathrm{C}$ );

- Hospital 4: garden 1-M1-19; garden 2-M2-19; reception hall -M3-19; hospital ward-M4-19 (year 2019-incubation in $37^{\circ} \mathrm{C}$ ).

\section{Methods of analysis}

The microbiological evaluation of the air can be performed with different analytical methods, each of them with its own specific advantages and disadvantages. The methods of aspiration, filtration and sedimentation are among the most important ones. The first two methods determine the microflora in known volumes of air, in special equipment, where the working principle is air flow's the shock effect of the air flow [Frashëri et al. 1997, Prifti et al. 2004].

Many authors have conducted comparative studies on two selected methods or used some of them, providing their respective evaluations [Napoli et al. 2012, Pallabi et al. 2018].

The comparison of results with different methods used was not part of this study. Only one method was applied, and the obtained results were compared over the years. The selected method was that of "passive sampling" [Index of Microbial Air Contamination (IMA)], which corresponds to the number of CFU counted on Petri dishes with a diameter of $9 \mathrm{~cm}, 1$ hour $/ 1 / \mathrm{m}$ above the floor $/ 1 \mathrm{~m}$ away of all obstacles. This scheme was selected based on the publications of the authors from neighboring countries, considering similarities in the ecological, geographic and infrastructure conditions in monitoring sites [Napoli et al. 2012, Pasquarella et al. 2000]. The selected method derives from the old classical method of sedimentation "rain of microbes", considering it an easy, inexpensive applicable method and with good results. The above-mentioned conditions were modified by changing the time of air falling and performing it with IMA 20 minutes $/ 1 \mathrm{~m}$ above the floor/the surrounding arearadius $1 \mathrm{~m}$ free. The modification was related to monitoring sites in general outdoor environments [Frashëri et al. 1997, Napoli et al. 2012, Pasquarella et al. 2000]. During the research, 6 IMA Petri dishes-9 mm diameter were used for each selected sample: 4 IMA Petri dishes with PCA (Plate Count Agar) media for TVC (Total Viable Count) of microorganisms were used for 2 parallel trials for each sample \& 2 IMA Petri dishes with SDA (Sabouraud Dextrose Agar) media for the determination of molds and yeasts were used for 2 parallel trials for each sample [Frashëri et al. 1997, Prifti et al. 2004, Stetzenbach et al. 2004]. Plate incubation was performed as follows:

- 2 IMA Petri dishes with PCA (Plate Count Agar) media for TVC (Total Viable Count) of microorganisms were incubated in $28-30^{\circ} \mathrm{C}$, to develop the total number (not pathogens).

- 2 IMA Petri dishes with PCA (Plate Count Agar) media were incubated in $37^{\circ} \mathrm{C}$, for pathogenic bacteria, mentioned in the above description of sampling (comparison of results).

- 2 IMA Petri dishes with SDA were incubated at $28-30^{\circ} \mathrm{C}$, to develop the total number of molds and yeasts (from the adapted theoretical information [Frashëri et al. 1997, Kurtzman et al. 2011], an insignificant number of yeasts were expected).

\section{RESULTS AND DISCUSSIONS}

The microbiological analysis of 8 monitored environments, using the methodological scheme detailed above, was presented in the following chart (TVC in CFU/Pd, with calculated average values found) (Fig. 1).

The results above confirm the values of the total number of microorganisms in order of $10^{1}$, and the number of molds and yeasts in order of $10^{\circ}$; in all the cases, the mold presence is about 10 times smaller than those of TVC values. The 


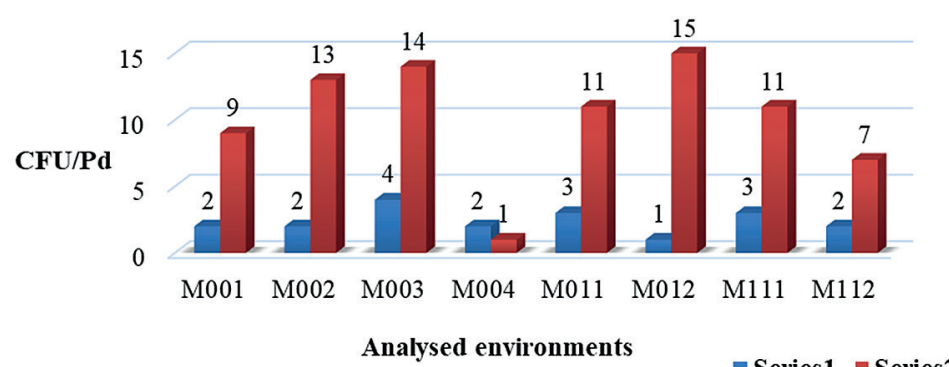

Figure 1. TVC in 8 analyzed hospital environments (series 2) The determined number of yeasts and molds (series 1)

situation had improved substantially compared to the results obtained from the previous studies (period 2000-2010), where the air had to be qualified microbiologically polluted when the loads exceeded the second order.

Gram positive cocci and Bacillus spp. dominated the identified bacterial loads. Bacillus megaterium was the dominant species of bacilli $(29 \%$ of total bacilli load). It is gram + , rod-shaped and aerobic, derived and spread out from the soil. It is classified as nonpathogenic, but in some cases, it is responsible for cutaneous infections [Fu-Ping et al. 2015]. It was present in the garden samples and maybe spread out by the dust rising in the air. Only one Escherichia coli was identified and there was no Streptococcus spp. In SDA media, the dominant molds were those of the genus $A s$ pergillus, about $48 \%$ of the total number of molds detected. About $80 \%$ of the molds from this genus belonged to Aspergillus niger, $10 \%$ to Aspergillus terreus, $1 \%$ to Aspergillus flavus, 9\% other species of Aspergillus genius (Fig. 2).

Aspergillus flavus was found in Hospital 1-garden M001 (sampling of 2018). It is a highrisk strain because it produces aflatoxins and can spread rapidly in neighboring environments. The presence of Aspergillus niger was expected because, in earlier works, it has also been

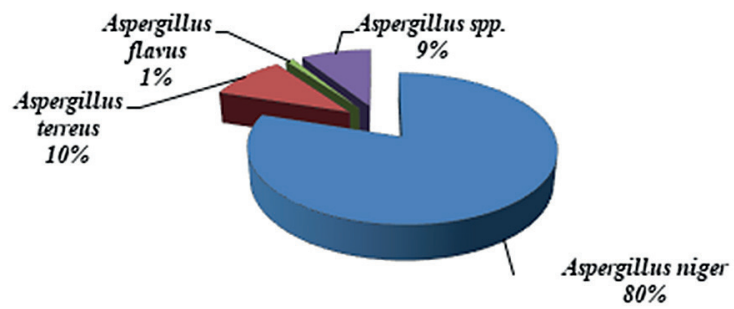

Figure 2. The presence of molds Aspergillus in SDA Petri dishes detected in vegetation areas and indoor surfaces. It is responsible for the so-called disease "black mold" on grapes and apricots. It was found in Hospital 2: hospital ward 1-M011 and Hospital 3: hospital ward 1-M111 (sampling of 2018). The fruits brought by visitors to the ward, could have been the source of this mold. It was located in the air due to the spores spread out. For the people who have weakened immune systems, breathing in the Aspergillus spores can cause an infection in the lungs or sinuses; therefore, it may be necessary to implement the measures for "controlled entry and exit" [Back et al. 2005, Raper et al. 1965].

Hospital 4 was heavily exposed to a construction area, with greater car traffic and population. The results of the microbiological air control of the samples of this hospital are detailed in the Table 1.

The maximum TVC value was found in Hospital 4-reception hall-M3. A dominance of Aspergillus species was noticed again. Hospital 4-patient room-M5 was the host of Rhodotorula species, not harmful, but important for biomolecules and carotene production (in rare cases, it causes allergic skin reactions).

The above-mentioned results of TVC from monitored environments of Hospital 4 (year 2018) were compared with those of the same period and of similar temperature values, in the years 2010 and 2019. The situation is presented in Figure 3.

As seen from the graph, the environments monitored over the years represent changes, depending on the influencing factors. High values of TVC were confirmed by a microbiological analysis of 2010 samples, where secondorder TVCs were also found (garden 1-M1-10; garden 2-M2-10). Meanwhile, the calculated TVC values for 2018 and 2019 are substantially lower and comparable between them. Both 
Table 1. Microbiological air evaluation in the samples selected in Hospital 4 (Year 2018)

\begin{tabular}{|c|c|c|c|c|}
\hline Sample Code & $\begin{array}{c}\text { Selected } \\
\text { Media }\end{array}$ & $\begin{array}{c}\text { CFU/Pd } \\
\text { average value }\end{array}$ & $\begin{array}{c}\text { Molds } \\
\text { Colony/ Pd }\end{array}$ & Identified microorganisms \\
\hline M1 & PCA & $3.6 \times 10^{1}$ & 9 & $\begin{array}{c}\text { Aspergillus flavus -7 colonies, } \\
\text { Aspergillus terreus- 2 colonies, } \\
\text { Pigmented Bacilli- 3 colonies. }\end{array}$ \\
\hline M2 & PCA & $3.3 \times 10^{1}$ & & $\begin{array}{c}\text { Dominant colonies: } \\
\text { Aspergillus terreus, } \\
\text { Bacillus cereus. }\end{array}$ \\
\hline M3 & PCA & $7.6 \times 10^{1}$ & $\begin{array}{c}\text { Dominant colonies: } \\
\text { Aspergillus terreus, } \\
\text { Aspergillus flavus, } \\
\text { Bacillus cereus. }\end{array}$ \\
\hline M4 & PCA & $5.1 \times 10^{1}$ & 2 & $\begin{array}{c}\text { Aspergillus flavus-2 colonies, } \\
\text { Bacillus cereus. }\end{array}$ \\
\hline M5 & PCA & $4.05 \times 10^{1}$ & 3 & $\begin{array}{c}\text { Rhodotorula specie, } \\
\text { Aspergillus flavus, } \\
\text { Aspergillus terreus. }\end{array}$ \\
\hline
\end{tabular}

The taxonomic study of molds - Molds (Colony/Pd) for the samples M1 and M2 -Hospital 4 was focused only on the strains mentioned above.

samples of Hospital 4: garden 1-M1-19 \& garden 2-M2-19 (year 2019) provided high values of microorganisms, which can be explained by the infrastructural changes that were implemented in the vicinity of sampling sites, where an in-depth work was currently being done on the structure of roads (earthworks involving the removal of topsoil, along with vegetation). The results of Figure 4 show that the number of indoor microorganisms did not depend on external environmental pollution, when the preventive measures were taken. It was at a very low level (the first order), even in highly populated indoor environments. There are apparently positive changes coming from the precautions taken indoors (periodic ventilation, cleaning, disinfection, increased responsiveness to patients and visitors, etc.).

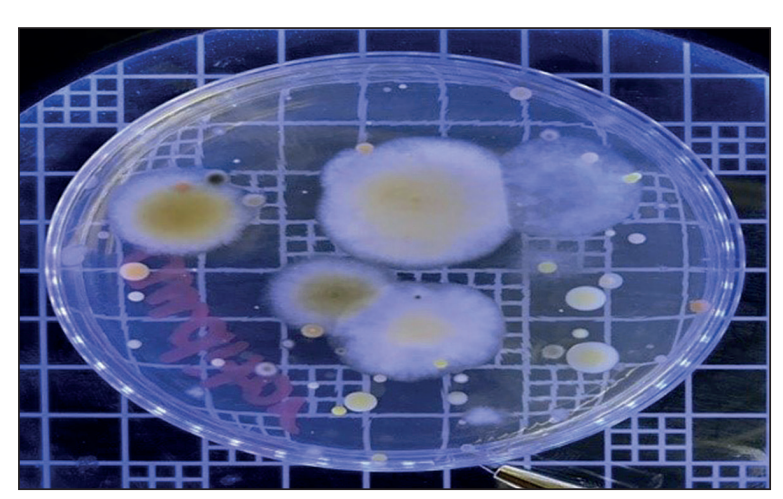

Figure 3. The counting of colonies in $\mathrm{PCA} / \mathrm{Pd}$, sample: Hospital 4 - hospital ward-M4

(Petri dish in an automated colony counting device).

\section{CONCLUSIONS}

1. The comparative study results over the years (2010-2018/2019) confirmed an improvement in the factors affecting the spread of saprophytic and pathogenic microorganisms in the Tirana hospital areas, by reducing the risk of hospital infections originating from the microbiological air pollution. In the experiments of 2010, the order of the loads of microorganisms present in the hospital areas was over $10^{2}$ (in some cases a very large microbial pollution-order $10^{3}$ ), while in 2019 the order was $10^{1}$.

2. Bacillus dominance was confirmed in our hospital settings, as expected from previous similar studies. This is due to their high resistance and because of no need for specific development conditions.

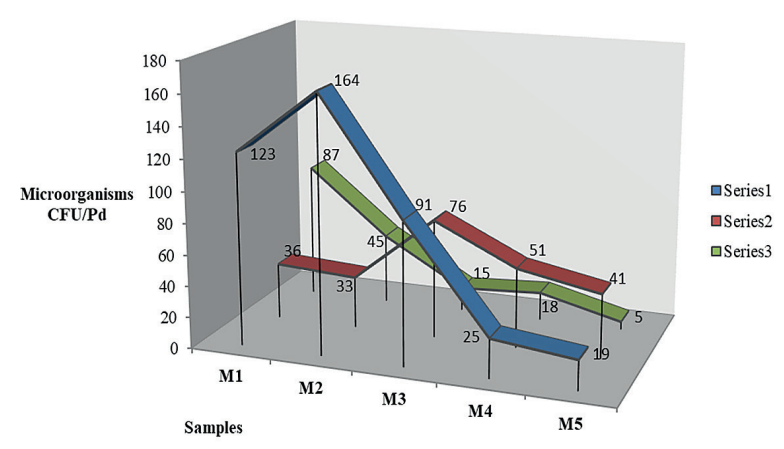

Figure 4. TVC of the monitoring environments of Hospital 4

Series 1 - Year 2010; Series 2 - Year 2018; Series 3 - Year 2019 
3. Various species such as Bacillus megaterium live and develop well in dusty environments and waste materials. Even in this case, Bacillus megaterium was estimated dominant, with $29 \%$ of total isolated bacilli. Clean open environments strongly reduce the presence of $b a$ cilli and prevent them from spreading within the hospital areas.

4. The lack of pathogens is associated with much more improved hygienic-sanitary conditions than the assessment from the past decade.

5. Referring to a large number of experiments over the years, a very negligible presence of yeasts was found. Their reduced presence has been identified only in the cases of microbiological evaluation of populated hospital environments, where foods or beverages such as fruit juice were consumed, or where their packaging materials were left. Evaluation of the presence of microbiological loads in random packaging materials, taken as the samples during microbiological air evaluation of the nearby hospital environments, confirmed the presence of yeasts.

6. The dominance of Aspergillus spp. was observed, but the presence of Aspergillus flavus (although only in 1\% of total isolated Aspergillus microorganisms), poses an increased risk, because this mold (together with Aspergillus parasiticus) produces aflatoxins. An in-depth study is suggested to reveal the origin of its presence in our observed hospital settings.

7. High prevalence of Aspergilus niger, (responsible for otomycosis - a microbial ear infection), compared with other observed species of the same genus was expected (about $80 \%$ of the total Aspergillus spp. isolated during the microbial evaluation of environments). The same results were obtained even in the previous experiments. This is also related to its multiple sources, as a usual contaminant of soil, dust, food and indoor environments. In the indoor hospital areas, the decrease of its presence is also related to the hygienic-sanitary measures, that reduce the growth of mold spores.

8. Referring to the experimental results of one of the hospitals under monitoring ( $\mathrm{H} 4)$, the impact of external infrastructure changes, has been clearly observed at the hospital and its indoor environments. In these cases, a preliminary plan is suggested, which should consider the location of the medical center, in order to minimize the damage caused by the infrastructure modifications to the external environment, even when they do not last for a long period of time and bring improvements to the existing infrastructure situation. In these cases, additional measures are suggested for cleaning and disinfection of the internal environments.

\section{REFERENCES}

1. Back W. 2005. Color Atlas and Handbook of Beverage Biology, Fachverlang Hans Carl, Nurnberg, Germany, ISBN 3-418-00799-6, pag. 1-309.

2. Bekkari H., Benchemsi N., Touijer H., Berrada S., Maniar S., Ettayebi M., El Ouali Lalami A., 2016. Microbial Analysis of Air in a Public Hospital in the City of Fez, Morocco, International Journal of Pharmaceutical and Clinical Research 2016; 8(6): pag. 533-537, ISSN- 09751556.

3. Ducel G. et al., 2012. Prevention des Infections Nosocomiales, Guide Practique, seconde edition, WHO/CDS/CSR/EPH 2002, pag.12.

4. Ekhaise FO, Isitor EE, Idehen O, Emoghene AO, 2010. Airborne Microflora in the Atmosphere of an Hospital Environment of University of Benin Teaching Hospital (UBTH), Benin City, Nigeria. World Journal of Agricultural Sciences 6: pag.166-170.

5. Frashëri M., Prifti D., 1997. "Practicum of Technical Microbiology" SHBLU-UT Publications; pag. $1-120$.

6. Fu-Ping G., Hong-Wei F., Zheng-Yin L., Qi-Wei Y., Yi-Jia L., and Tai-Sheng L., 2015. Brain Abscess Caused by Bacillus megaterium in an Adult Patient. Chin Med J (Eng.), Jun 5; 128(11): pag.1552-1554.

7. Grisoli P., Albertoni M., Rodolfi M., 2019. Application of Airborne Microorganism Indexes in Offices, Gyms and Libraries, Applied Sciences, 2019,9,1101; doi: 10.3390/app9061101.

8. Haleem A.A., Karuppayil K.S.M., 2012, Fungal Pollution of Indoor Environments and its Management, Vol.19, Issue 4, October 2012, pag. 405-426.

9. Kika B., Llagami A., 2014. Mikrobiologjia e Infeksioneve Spitalore-Modul 3, Albanian Association of Industrial Environmentalists Statistical Research Center, Information \& Technology, Aaie-Src\&It, Tiranë, Albania. http://www.srcit.org

10. Kurtzman C. Fell. J.W., Boekhout Teun 2011. The Yeasts a Taxonomic Study. Elsevier, USA.

11. Napoli Ch., Marcotrigiano V., Montagna M.T., 2012. Air Sampling Procedures to Evaluate Microbial Contamination: a comparison between active and passive methods in operating theatres. BMC Public Health -12-594 
12. Pasquarella C, Pitzurra O, Savino A., 2000. The Index of Microbial Air Contamination. The Journal of Hospital Infection; 46(4), 241-256. doi: 10.1053/ jhin.2000.0820.

13. Pallabi Pati, 2018. Review on Common Microbiological Contamination Found in Hospital Air, J. Microbiol. Pathol. 2018, 2(1), 103, Department of Microbiology, National Health Mission, Odessa, India.

14. Prifti D., Troja R., Shabani L., Xhangolli L., Petre A., 2004. Air Microflora in Tirana Environments. Shtypshkronja M. DURI, pp. 100.

15. Qudiesat K, Abu-Elteen K, Elkarmi A, Hamad M, Abussaud M., 2009. Assessment of Airborne Pathogens in Healthcare Settings. African Journal of Microbiology Research 3, 66-76.

16. Raper K., Fennell D., 1965. The Genus Aspergillus. The Williams and Willkins Company, Baltimore,
USA, vol. I, 103-113.

17. Syed A. Sattar, Richard J. Kibbee, et al., 2016. Decontamination of indoor air to reduce the risk of airborne infections: Studies on survival and inactivation of airborne pathogens using an aerobiology chamber. American Journal of Infection Control. 44(10), 177-182.

18. Stetzenbach L.D., Buttner M.P., Cruz P., 2004, Detection and Enumeration of Airborn Biocontaminant. Current Opinion in Biotechnology, 15(3), 170-174.

19. Traistaru E., Moldovan R.C., Menelaou A., et al., 2013. A Comparative Study on the Quality of Air in Offices and Homes. J. Environ.Sci. Health, 48, 1806-1814.

20. Troja R. 2014, Food Chemistry and Food Technology, SHBLU, pp. 300. 